\title{
Low-level X Chromosome Mosaicism: A Common Finding in Women Undergoing IVF
}

\author{
SOPHIA ZACHAKI ${ }^{1,2^{*}}$, ELISAVET KOUVIDI ${ }^{1 *}$, AMELIA PANTOU $^{1}$, HAROULA TSAROUHA $^{1}$, \\ ANASTASIOS MITRAKOS ${ }^{1}$, GEORGIA TOUNTA ${ }^{1}$, IOANNA CHARALAMPOUS ${ }^{1}$, \\ KALLIOPI N. MANOLA ${ }^{2}$, EMMANUEL KANAVAKIS ${ }^{1}$ and ARIADNI MAVROU ${ }^{1}$ \\ ${ }^{1}$ Genesis Genoma Lab, Genetic Diagnosis, Clinical Genetics \& Research, Athens, Greece; \\ ${ }^{2}$ Laboratory of Health Physics, Radiobiology \& Cytogenetics, \\ Demokritos National Center for Scientific Research (NCSR), Athens, Greece
}

\begin{abstract}
Background/Aim: To determine the incidence of $X$ chromosome mosaicism in women undergoing in vitro fertilization (IVF) treatment and present preimplantation genetic testing for aneuploidy (PGT-A) outcome of this group. Patients and Methods: A total of 1,058 women undergoing IVF and 154 women with no fertility problems were enrolled in the study. Karyotyping from peripheral blood lymphocytes was performed by conventional cytogenetics. Twenty-nine women with $X$ mosaicism underwent PGT-A by arraycomparative genomic hybridization from embryos at the blastocyst stage. Results and Conclusion: Out of 1,058 women undergoing IVF, 166 (15.7\%) had an abnormal karyotype. The most common finding (14.6\%) was $X$ chromosome mosaicism. Its frequency was higher in women $>35$ years old and reached $46.1 \%$ in those $>45$ years of age. $P G T-A$ results of 130 blastocysts tested showed that 29/117 $(24.8 \%)$ were euploid; $17 / 29$ (60\%) were transferred and $10 / 17(70 \%)$ were successfully implanted, indicating that PGT-A may be an option for women with low-level $X$ chromosome mosaicism undergoing IVF in order to improve the likelihood of a successful pregnancy outcome.
\end{abstract}

Infertility is a multifactorial disease of the reproductive system and is defined as failure of a couple to achieve conception and childbirth after 12 months of regular

This article is freely accessible online.

*These Authors contributed equally to this study.

Correspondence to: Sophia Zachaki, MSc, Ph.D., Genesis Genoma Lab, Genetic Diagnosis, Clinical Genetics \& Research, Athens, Greece. Tel: +30 2106803130, Fax: +30 2106894778, e-mail: szachaki@gmail.com.

Key Words: Chromosomal abnormalities, aneuploidy, $\mathrm{X}$ mosaicism, preimplantation genetic testing for aneuploidy, PGT-A. unprotected sexual intercourse. Clinically, it is highly heterogeneous, with a complex etiology that implicates lifestyle, environmental and genetic factors, including specific gene mutations and chromosomal abnormalities, such as numerical sex chromosome abnormalities, parental balanced translocations and inversions. Current studies indicate that the incidence of chromosomal abnormalities is higher in infertile couples than in the general population and ranges from 1.3 to $15 \%$, if one includes chromosomal polymorphisms (1-4).

The most frequently observed chromosomal abnormality in women with infertility is $\mathrm{X}$ chromosome mosaicism, usually $45, \mathrm{X} / 46, \mathrm{XX}$ or $47, \mathrm{XXX} / 46, \mathrm{XX}$. Although X chromosome inactivation is a well-known phenomenon in all somatic cells, the presence of both $\mathrm{X}$ chromosomes in oocytes is very important for normal gametogenesis, since several ovarian function-associated genes are located on the $\mathrm{X}$ chromosome (5). In order to equalize the dose of genetic material between females and males, one of two $\mathrm{X}$ chromosomes in women is inactivated early during fetal development, at gastrulation (6). Inactivation occurs randomly in each cell and the inactivation pattern remains in all mitotic divisions derived from the original cell (6). During gametogenesis, the inactivated $\mathrm{X}$ is reactivated before meiotic division and remains active. Thus, women having $\mathrm{X}$ chromosome mosaicism in their karyotype are at increased risk of exhibiting chromosomal instability and consequently aneuploid gametes (7).

$\mathrm{X}$ Chromosome mosaicism can be generated by the proliferation of cells in culture (artifact), being true mosaic or due to a woman's advanced age $(5,8)$. Mosaicism due to culture conditions is relatively easy to distinguish as it involves a limited number of cells and aneuploidy not only of the $\mathrm{X}$ chromosome but also of other chromosomes. True mosaicism and age-related mosaicism, however, are difficult to distinguish and their clinical significance is not fully understood.

Of particular interest is the high frequency of women who display low-level X chromosome mosaicism. In the literature, the percentage of aneuploid cells below which mosaicism is 
considered as low-level ranges between $4 \%$ and $10 \%(1-4,9)$. In the present study, based on European Cytogeneticists Association guidelines, the limit of low-level mosaicism was set at $10 \%$ and of true mosaicism at $15 \%$ (10). Given that the existence of low-level mosaicism of $45, \mathrm{X} / 46, \mathrm{XX}$ has been reported even in women with normal reproductive capacity (11), the significance of $\mathrm{X}$ mosaicism in fertility of female carriers, particularly in cases with low aneuploid cell counts $(<6-10 \%$ of cells), remains unclear $(1-4,9)$.

The purpose of this study was to determine the incidence and types of $\mathrm{X}$ chromosome mosaicism in women undergoing an in vitro fertilization (IVF) cycle. Furthermore, since preimplantation genetic testing for aneuploidy (PGTA) may be an option for couples with chromosomal abnormalities, data from blastocysts tested by arraycomparative genomic hybridization were included in this study in order to estimate the benefit of employing the PGTA technique in the success of IVF.

\section{Patients and Methods}

Study population. A total of 1,058 women who were referred to the GENESIS Athens clinic for IVF between June 2016 and June 2018 were enrolled in the study (mean age $=40.8$ years, range $=28-50$ years). The control group included 154 women who were referred to the clinic for the annual gynecological examination (mean age $=32.3$ years; range 28-50). The criteria for the selection of the control group were women with a regular menstrual cycle, no history of uterine malformations and normal gynecological and ultrasound examination. The survey complied with the requirements of The Helsinki Declaration (1975). All participants gave their written consent for anonymous and voluntary participation in the study.

Chromosome G-banding analysis. Cytogenetic analysis was performed on phytohemagglutinin-stimulated peripheral blood lymphocytes by GTG banding according to standard laboratory protocols. For each woman, 25 metaphases were analyzed, eight of which were karyotyped using Ikaros Metasystems imaging software (MetaSystems, Newton, MA, USA). Karyotypes were described according to the 2016 International System for Human Cytogenetic Nomenclature (12). When one cell with sex chromosome aneuploidy (loss or gain) was detected in the first 25 metaphases, the analysis was extended to 100 metaphases. X Chromosome mosaicism of $<4 \%$ was not reported. Based on European Cytogeneticists Association guidelines, the borderline of low-level mosaicism was considered to be $10 \%$, while true mosaicism was considered as the presence of $>15 \%$ of aneuploid cells (10). Chromosomal polymorphisms such as large satellites, increased heterochromatic regions, and small pericentric inversions were not reported.

$P G T-A$. PGT-A was performed using microarray comparative genomic hybridization on day 5/6 blastocyst biopsies from 29 women with $\mathrm{X}$ chromosome aneuploidy. Array comparative genomic hybridization technique detects not only numerical chromosomal aberrations but also smaller gains or losses of genetic material. Whole genome amplification was initially performed to amplify the entire genome of the cells deriving from the blastocysts, using the
REPLI-g Single Cell Kit (Qiagen, Hilden, Germany) according to the manufacturer's instructions. Molecular karyotyping of the blastocysts was performed using Genetisure Pre-Screen kit 8x60K (Agilent Technologies, Santa Clara, CA, USA) according to the manufacturer's instructions. The CytoGenomics Software (Agilent Technologies) was used to analyze and evaluate the data obtained.

Statistical analysis. Statistical analysis was performed using Statistical Package for the Social Sciences software (version 20; IBM, Armonk, NY, USA). Pearson chi-square and Fisher's exact tests were used to assess the relationship of mosaicism with age and percentage of aneuploid cells. Values of $p<0.05$ were considered significant. Odds ratios (ORs) are given with $95 \%$ confidence interval (CI).

\section{Results}

A total of 892 out of 1,058 women $(84.3 \%)$ had normal karyotypes, while 166 women (15.7\%) had abnormal karyotypes; 12 women $(1.1 \%)$ had abnormalities of autosomal chromosomes and 154 (14.6\%) had X chromosome abnormalities (Table I). Autosomal abnormalities included five reciprocal translocations, four Robertsonian translocations and three paracentric/large pericentric inversions. Among the 154 women with $\mathrm{X}$ chromosome aneuploidy, $139(90.3 \%)$ showed low-level mosaicism $(<10 \%), 12(7.8 \%)$ had mosaicism that ranged from $10-15 \%$ and three $(1.9 \%)$ had true mosaicism $>15 \%$. The mean age of women exhibiting low-level mosaicism was 40.5 years, while that of women exhibiting mosaicism ranging from $10-15 \%$ was 43.2 years and of women with true mosaicism was 44.3 years.

Out of 154 healthy women used as controls, 142 (92.2\%) had normal karyotype and $12(7.8 \%)$ had low-level $\mathrm{X}$ chromosome mosaicism. None of these women presented mosaicism $>10 \%$ (Table I). Statistical analysis verified that the incidence of mosaicism was significantly higher in the study group as compared to the control population $(14.6 \%$ vs. $\left.7.8 \%, \mathrm{x}^{2}=5.41, d f=1, p<0.05\right)$.

Women enrolled in the study were categorized into three age-groups: $28-34,35-45$ and $>45$ years old. The frequency of $\mathrm{X}$ mosaicism in women undergoing IVF was $13 / 278$ $(4.7 \%), 106 / 704(15.1 \%)$ and 35/76 (46.1\%), respectively. The incidence of $\mathrm{X}$ mosaicism was statistically significantly higher in older women compared to younger ones $\left(x^{2}=29.6\right.$, $d f=1, p<0.001)$. Moreover, in the control group the frequency of the $\mathrm{X}$ mosaicism was calculated as $10 / 121$ (8.3\%), 2/28 $(7.1 \%)$ and $0 / 5(0.0 \%)$, in each age group, respectively. No statistically significant differences were observed between infertile women $\leq 34$ years and control women of the same age subgroup. On the contrary, $\mathrm{X}$ chromosome aneuploidy was higher in women $>35$ years of age undergoing IVF as compared to the controls of corresponding age $(18.1 \%$ and $6.1 \%, \chi^{2}=3.15, d f=1, p=0.076$, respectively). 
Table I. Chromosomal abnormalities in 1,058 women undergoing in vitro fertilization (IVF) and in 154 healthy women.

\begin{tabular}{lcc}
\hline & $\begin{array}{c}\text { Women } \\
\text { undergoing IVF } \\
(\mathrm{n}=1,058), \mathrm{n}(\%)\end{array}$ & $\begin{array}{c}\text { Control } \\
\text { population } \\
(\mathrm{n}=154), \mathrm{n}(\%)\end{array}$ \\
\hline Karyotype & & \\
$\quad$ Normal & $892(84.3 \%)$ & $142(92.2 \%)$ \\
$\quad$ Abnormal & $166(15.7 \%)$ & $12(7.8 \%)$ \\
Autosomal abnormalities & & \\
$\quad$ Total & $12(1.1 \%)$ & $0(0.0 \%)$ \\
Reciprocal translocation & $5(0.5 \%)$ & $0(0.0 \%)$ \\
Robertsonian translocation & $4(0.3 \%)$ & $0(0.0 \%)$ \\
Inversions & $3(0.3 \%)$ & $0(0.0 \%)$ \\
SeX chromosome & & \\
abnormalities & & $12(7.8 \%)$ \\
Total & $154(14.6 \%)$ & $7(4.5 \%)$ \\
$45, \mathrm{X} / 46, \mathrm{XX}$ & $54(5.1 \%)$ & $0(0.0 \%)$ \\
$47, \mathrm{XXX} / 46, \mathrm{XX}$ & $2(0.2 \%)$ & $5(3.2 \%)$ \\
$45, \mathrm{X} / 47, \mathrm{XXX} / 46, \mathrm{XX}$ & $94(8.9 \%)$ & $0(0.0 \%)$ \\
$45, \mathrm{X} / 48, \mathrm{XXXX} / 47, \mathrm{XXX} / 46, \mathrm{XX}$ & $4(0.4 \%)$ & \\
\hline
\end{tabular}

Among women who had X chromosome aneuploidy, 56 had two cell lines (54 had $45, \mathrm{X} / 46, \mathrm{XX}$ and two had $47, \mathrm{XXX} / 46, \mathrm{XX}), 94$ had three cell lines $(45, \mathrm{X} / 47, \mathrm{XXX} / 46$, $\mathrm{XX})$ and four had four $(45, \mathrm{X} / 47, \mathrm{XXX} / 48, \mathrm{XXXX} / 46, \mathrm{XX})$ (Table II). The number of aneuploid cell lines was observed to increase in older women: $6 / 13(46.0 \%), 66 / 106(62.3 \%)$ and $26 / 35$ (74.3\%), respectively.

From the enrolled women with $\mathrm{X}$ chromosome aneuploidy, 29 (mean age=39.1 years) decided to undergo PGT-A after evaluation of all parameters including maternal age, ethical issues and economic status. In total, 130 blastocysts were tested. Of those, diagnosis was feasible in 117 (90\%); only $29 / 117$ blastocysts $(24.8 \%)$ were euploid and considered appropriate for embryo-transfer. The mean number of embryos per embryo-transfer was 1.7 , the implantation rate was $10 / 17(58.8 \%)$ and live birth rate $7 / 10$ $(70 \%)$. Results are shown in Table III.

\section{Discussion}

The results of the present study confirm that the most common chromosomal abnormality in women with reproductive problems is $\mathrm{X}$ chromosome mosaicism $(1-4,9)$. Interestingly, in the present study the frequency of $\mathrm{X}$ chromosome mosaicism in women more than 45 years old undergoing IVF was $46.1 \%$, especially indicating the need for karyotypic analysis of these women. Loss of one $\mathrm{X}$ chromosome is reportedly the more frequent finding $(45, \mathrm{X} / 46, \mathrm{XX})$, while in several cases, two or more aneuploid karyotypes were present $(13,14)$.
The frequency of $\mathrm{X}$ chromosome mosaicism in women of the study group was estimated at $14.6 \% ; 13.2 \%$ exhibited lowlevel $\mathrm{X}$ chromosome mosaicism $<10 \%, 1.1 \%$ had mosaicism $10-15 \%$ and $0.3 \%$ had true mosaicism $>15 \%$. In the literature, the incidence of low-level $\mathrm{X}$ mosaicism in women with fertility problems ranges between $2.77 \%$ and $16 \%(10,15)$. This wide range is probably due to various sample selection criteria and differences in the methodological approach, such as the number of cells analyzed and the minimum proportion of aneuploid cells considered significant. The frequency of $\mathrm{X}$ chromosome mosaicism in women undergoing IVF was significantly higher as compared to the control population ( $14.6 \%$ vs. $7.8 \%$, respectively). These percentages are comparable to the corresponding rates reported in similar studies $(1-4,8-9,15)$.

In the present study, the incidence of $\mathrm{X}$ chromosome mosaicism was statistically significantly higher in older women as compared to the younger ones, reaching $46.1 \%$ in those over 45 years old. Moreover, the mean age was higher in women who exhibited mosaicism $>10 \%$ compared to those who exhibited low-level mosaicism (<10\%; $43.2 \mathrm{vs}$. 40.5 years, respectively). These findings confirm previous studies indicating increasing loss of $\mathrm{X}$ chromosome with increasing age $(8,13-15)$. It has been reported that fewer than $1 \%$ of women of the general population aged under 25 years exhibited mosaic $45, \mathrm{X} / 46, \mathrm{XX}$ in their karyotype, while $7.3 \%$ of those aged 65 years exhibited this (8). In contrast, women with premature ovarian insufficiency showed lowlevel mosaicism ( $\leq 10 \%$ of aneuploid cells) in $10.5 \%$ and true mosaicism (which they defined as $>10 \%$ of aneuploid cells) in $11.4 \%$. The same study also reported that the mean age of those women with low-level mosaicism was 35.92 \pm 3.87 years, whereas that of those exhibiting true mosaicism was significantly lower at 26.0 \pm 5.65 years (5).

The exact mechanism by which one $\mathrm{X}$ chromosome is lost in older women has not been fully elucidated. In most studies it is reported, however, that the $\mathrm{X}$ chromosome lost is the inactivated one (16). This is probably due to the phenomenon of premature division of the centromere (premature centromere division) (17). This phenomenon is associated with mutations of budding uninhibited by benzimidazoles 1 gene (BUBlB; OMIM 602860), which encodes a protein that plays a critical role in regulating the spindle-assembly checkpoint, affecting mainly the inactivated $\mathrm{X}$ chromosome in older women. Another approach concerns chromosome telomeres, the repetitive sequences (TTAGGG)(n) at the ends of the chromosomes that decrease in length both during DNA replication and in response to oxidative stress. The length of the oocyte telomeres is related to a woman's age, since in older women the oocytes have undergone more mitotic cycles before ovulation. Experimental shortening of telomeres in mice reduced synapsis and chiasmata, increased embryo 
Table II. Frequency of each type of X chromosome mosaic karyotype in women undergoing in vitro fertilization according to age.

\begin{tabular}{lrrrrr}
\hline & & \multicolumn{3}{c}{ Karyotype, $\mathrm{n}(\%)$} \\
\cline { 3 - 5 } Age, years & $\mathrm{N}$ & $45, \mathrm{X} / 46, \mathrm{XX}$ & $47, \mathrm{XXX} / 46, \mathrm{XX}$ & $45, \mathrm{X} / 47, \mathrm{XXX} / 46, \mathrm{XX}$ & $45, \mathrm{X} / 47, \mathrm{XXX} / 48, \mathrm{XXXX} / 46, \mathrm{XX}$ \\
\hline $28-34$ & 13 & $7(53.8 \%)$ & $0(0.0 \%)$ & $5(38.5 \%)$ & $1(7.7 \%)$ \\
$35-45$ & 106 & $39(36.8 \%)$ & $1(0.9 \%)$ & $64(60.4 \%)$ & $2(1.9 \%)$ \\
$>45$ & 35 & $8(22.9 \%)$ & $1(2.8 \%)$ & $25(71.4 \%)$ & $1(2.9 \%)$ \\
\hline
\end{tabular}

fragmentation, and led to cell-cycle arrest, apoptosis, spindle dysmorphologies and chromosomal abnormalities (18).

Interestingly, the findings of the present study show that the number of aneuploid cell lines also increased in older women. It is noteworthy that women $>45$ years of age more frequently had three or four cell lines as compared to younger women. This may be due to general chromosomal instability and deterioration of the mitotic spindle in women of advanced age, which mainly arise because of chromosome segregation patterns such as non-disjunction, premature separation of sister chromatids or recent reverse segregation (7).

In the past few years, couples carrying chromosomal abnormalities have been able to benefit from PGT-A in order to identify euploid blastocysts for embryo-transfer during IVF, thereby improving pregnancy success and avoiding having children with chromosomal abnormalities. It would be advisable for women of advanced reproductive age exhibiting $\mathrm{X}$ mosaicism to undergo PGT-A given the fact that they are at increased risk of producing aneuploid oocytes. The low percentage of euploid blastocysts $(24.8 \%)$, the significant successful implantation rate among euploid embryos $(\sim 60 \%)$ and live birth rate of $70 \%$ reported in the present study should be taken into account for the selection of an appropriate protocol for assisted reproduction. In any case, prenatal diagnosis is strongly recommended.

The clinical significance of low-level $\mathrm{X}$ chromosome mosaicism and its association with female infertility has not been fully elucidated. The karyotype of peripheral blood lymphocytes for the detection of mosaicism does not necessarily reflect the true percentage of aneuploid oocytes However, it is the standard method of cytogenetic analysis and can provide important information on the existence of possible chromosomal abnormalities that hinder successful reproduction in infertile couples. In particular, in couples to be enrolled in an assisted reproduction protocol, cytogenetic findings should be taken into consideration and genetic counseling should be offered so that these couples can be offered better management. Moreover, for cases in which a chromosome abnormality such as $\mathrm{X}$ chromosome mosaicism is found, PGT-A is recommended in order to improve pregnancy outcome.
Table III. Outcome following preimplantation genetic testing for aneuploidy (PGT-A) for 29 couples underwent preimplantation genetic diagnosis for selection of euploid embryos.

\begin{tabular}{lc}
\hline PGT-A data & $\mathrm{n}(\%)$ \\
PGT-A cycles & 29 \\
Blastomeres & \\
$\quad$ Analyzed & 130 \\
Diagnosed & $117 / 130(90.0 \%)$ \\
Euploid & $29 / 117(24.8 \%)$ \\
Embryo-transfer & $17 / 29(58.6 \%)$ \\
Implantation & \\
Total & $10 / 17(58.8 \%)$ \\
Aborted & $3 / 10(30.0 \%)$ \\
Live birth & $7 / 10(70.0 \%)$ \\
\hline
\end{tabular}

\section{Conflicts of Interest}

The Authors have no conflicts of interest to declare.

\section{Authors' Contributions}

SZ and EK contributed to the design of the study, cytogenetic analyses, interpretation of the results, data collection, data analysis and manuscript preparation; HT contributed to cytogenetic analyses and interpretation of the results; AP, AM, GT contributed to PGT-A analyses and interpretation of the results; IC provide technical support in the various steps of the study; KM contributed to manuscript editing; EK coordinated the various steps of the study; AM had the overall study supervision. All Authors read and approved the final manuscript.

\section{Acknowledgements}

The Authors would like to thank the gynecologists of the Athens Genesis Clinic for the monitoring of women, embryo biopsies and their overall support for the implementation of the study. Moreover, the Authors thank the Stavros Niarchos Foundation (SNF) for supporting the study.

\section{References}

1 Gekas J, Thepot F, Turleau C, Siffroi JP, Dadoune JP, Briault S, Rio M, Bourouillou G, Carré-Pigeon F, Wasels R and Benzacken B; Association des Cytogeneticiens de Langue Francaise: Chromosomal factors of infertility in candidate couples for ICSI: 
An equal risk of constitutional aberrations in women and men. Hum Reprod 16(1): 82-90, 2001. PMID: 11139542. DOI: 10.1093/humrep/16.1.82

2 Sonntag B, Meschede D, Ullmann V, Gassner P, Horst J, Nieschlag E and Behre HM: Low-level sex chromosome mosaicism in female partners of couples undergoing ICSI therapy does not significantly affect treatment outcome. Hum Reprod 16(8): 1648-1652, 2001. PMID: 11473957. DOI: 10.1093/ humrep/16.8.1648

3 Peschka B, Leygraaf J, Van der Ven K, Montag M, Schartmann B, Schubert R, van der Ven $\mathrm{H}$ and Schwanitz G: Type and frequency of chromosome aberrations in 781 couples undergoing intracytoplasmic sperm injection. Hum Reprod 14(9): 22572263, 1999. PMID: 10469691. DOI: 10.1093/humrep/14.9.2257

4 Meschede D, Lemcke B, Exeler JR, De Geyter C, Behre HM, Nieschlag E and Horst J: Chromosome abnormalities in 447 couples undergoing intracytoplasmic sperm injection-prevalence, types, sex distribution and reproductive relevance. Hum Reprod 13(3): 576582,1998. PMID: 9572415. DOI: 10.1093/humrep/13.3.576

5 Gersak K and Veble A: Low-level X chromosome mosaicism in women with sporadic premature ovarian failure. Reprod Biomed Online 22(4): 399-403, 2011. PMID: 21334258. DOI: 10.1016/j.rbmo.2011.01.002

6 Lyon MF. Gene Action in the X-chromosome of the Mouse (Mus musculus L.). Nature 190: 372-373, 1961. PMID: 13764598. DOI: $10.1038 / 190372 \mathrm{a} 0$

7 Cimadomo D, Fabozzi G, Vaiarelli A, Ubaldi N, Ubaldi FM and Rienzi L: Impact of maternal age on oocyte and embryo competence. Front Endocrinol 9: 327, 2018. PMID: 30008696. DOI: $10.3389 /$ fendo. 2018.00327

8 Russell LM, Strike P, Browne CE and Jacobs PA: X Chromosome loss and ageing. Cytogenet Genome Res 116(3): 181-185, 2007. PMID: 17317957. DOI: $10.1159 / 000098184$

9 Morel F, Gallon F, Amice V, Le Bris MJ, Le Martelot MT, Roche S, Valéri A, Derrien V, Herry A, Amice J and De Braekeleer M: Sex chromosome mosaicism in couples undergoing intracytoplasmic sperm injection. Hum Reprod 17(10): 2552-2555, 2002. PMID: 12351527. DOI: 10.1093/ humrep/17.10.2552

10 Madan $\mathrm{K}$ and Lundberg E: Low grade mosaicism for $\mathrm{X}$ aneuploidy in women referred for recurrent abortions. European Cytogeneticists Association Newsletter No. 35, pp. 9-12, 2015.
11 Horsman DE, Dill FJ, McGillivray BC and Kalousek DK: X Chromosome aneuploidy in lymphocyte cultures from women with recurrent spontaneous abortions. Am J Med Genet 28(4): 981-987, 1987. PMID: 3688037. DOI: 10.1002/ajmg.1320280425

12 McGowan-Jordan J, Simons A and Schmid M: ISCN 2016: An International System for Human Cytogenomic Nomenclature 12. McGowan-Jordan J, Simons A and Schmid M (eds.). Basel, S. Karger; 2016.

13 Nowinski GP, Van Dyke DL, Tilley BC, Jacobsen G, Babu VR, Worsham MJ, Wilson GN and Weiss L: The frequency of aneuploidy in cultured lymphocytes is correlated with age and gender but not with reproductive history. Am J Hum Genet 46(6): 1101-1111, 1990. PMID: 2339703.

14 Guttenbach M, Koschorz B, Bernthaler U, Grimm T and Schmid M: Sex chromosome loss and aging: In situ hybridization studies on human interphase nuclei. Am J Hum Genet 57(5): 1143-1150, 1995. PMID: 7485166.

15 Capkova P, Santava A, Krskova M, Adamova K, HladikovaZborilova B, Nedomova R, Sobek A, Curtisova V and Dhaifalah I: Low-level gonosomal mosaic (LLGM) in female reproduction. Obstet Gynaecol 2014: 884168, 2014. DOI: 10.5171/ 2014.884168

16 Hando JC, Tucker JD, Davenport M, Tepperberg J and Nath J: $\mathrm{X}$ chromosome inactivation and micronuclei in normal and Turner individuals. Hum Genet 100(5-6): 624-628, 1997. PMID: 9341883. DOI: $10.1007 / \mathrm{s} 004390050564$

17 Fitzgerald PH: A mechanism of X chromosome aneuploidy in lymphocytes of aging women. Humangenetik 28(2): 153-158, 1975. PMID: 1150269. DOI: 10.1007/bf00735748

18 Kalmbach KH, Fontes Antunes DM, Dracxler RC, Knier TW, Seth-Smith ML, Wang F, Liu L and Keefe DL: Telomeres and human reproduction. Fertil Steril 99(1): 23-29, 2013. PMID: 23273986. DOI: $10.1016 /$ j.fertnstert.2012.11.039
Received January 14, 2020

Revised February 17, 2020

Accepted February 21, 2020 